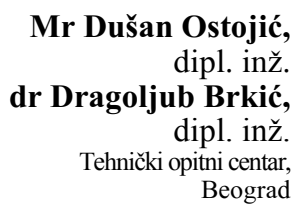

\section{ODREĐIVANJE POUZDANOSTI I RASPOLOŽIVOSTI JEDNOG TELEKOMUNIKACIONOG SISTEMA METODOM „MONTE KARLO“}

UDC: $519.245: 621.39$

Rezime:

U radu je predstavljena primena aproksimativne metode „,Monte Karlo“ za određivanje pouzdanosti i raspoloživosti telekomunikacionog sistema. Za predloženu simulacionu metodu urađen je odgovarajući računarski program koji je proveren na jednom ilustrativnom primeru.

Ključne reči: pouzdanost, raspoloživost, telekomunikacioni sistemi, metoda „Monte Karlo“, simulacija.

\title{
CALCULATION OF RELIABILITY AND AVAILABILITY OF TELECOMMUNICATION SYSTEM BY USING MONTE CARLO METHOD
}

Summary:

In this paper, the approximative method for determination the reliability and availability of a telecommunication system is described. This approximative method is based on the Monte Carlo method. For this purpose, the specially computer program was developed, by wich the validity of this proposed method was verified. Application of this method is illusrated by one example.

Key words: reliability, availability, telecommunication system, Monte Carlo method, simulation.

\section{Uvod}

Telekomunikacioni sistemi obezbeđuju brz i efikasan prenos informacija od njihovog izvora do krajnjeg korisnika. Uporedo sa razvojem sve složenijih telekomunikacionih sistema logično je da se javlja i problem njihovog pouzdanog funkcionisanja. Primena telekomunikacionih sistema za specijalne namene u svakom trenutku zahteva očuvanje visokog nivoa kvaliteta sistema radi obezbeđenja neprekidnosti komunikacija. Pošto se radi o popravljivim sistemima specijalne namene, kod kojih se održavanje može vršiti u određenom intervalu, pouzdanost i raspoloživost predstavljaju dva najvažnija pokazatelja kvaliteta.

Pouzdanost telekomunikacionog sistema predstavlja verovatnoću, sa određenim nivoom poverenja, da će sistem obezbediti prenos informacija u vremenu $t$, pod propisanim radnim režimima $\mathrm{i}$ uslovima okoline.

Kada su u pitanju sistemi naoružanja, pouzdanost direktno utiče na borbenu gotovost. Ako je pouzdanost jednog takvog sistema $50 \%$, onda je efektivni broj ovakvih raspoloživih sistema jednak najviše jednoj polovini stvarnog broja tih 
sistema. Kada se ova činjenica ne bi uzela u obzir, smatralo bi se da je pouzdanost ovih sistema $100 \%$, iako je stvarna situacija drugačija. To znači da se, pored ekonomskog aspekta i po pitanju bezbednosti mora poznavati nivo pouzdanosti sistema naoružanja radi planiranja njihovog efektivnog broja a ne samo fizičkog broja.

Raspoloživost telekomunikacionog sistema predstavlja verovatnoću, sa određenim nivoom poverenja, da će sistem obezbediti zadovoljavajući prenos informacija u trenutku vremena $t$, pod propisanim radnim režimima i uslovima okoline, uz mogućnost brze popravke, tj. dobre logističke podrške (raspoloživ alat, oprema, rezervni delovi i obučeno osoblje).

Funkcija pouzdanosti $R(t)$ predstavlja verovatnoću rada sistema $u$ intervalu vremena od 0 do t, a funkcija raspoloživosti $A(t)$ definiše se kao verovatnoća da će sistem raditi u trenutku vremena $t$.

Odnos funkcija pouzdanosti $R(t)$ i raspoloživosti $A(t)$ prikazan je na sledećem primeru:

ako je za neki sistem $R(350)=0,95$ i ako je 100 takvih sistema radilo 350 časova, u proseku je 95 sistema radilo bez otkaza u toku 350 časova dok je 5 sistema otkazalo u nekim vremenima unutar

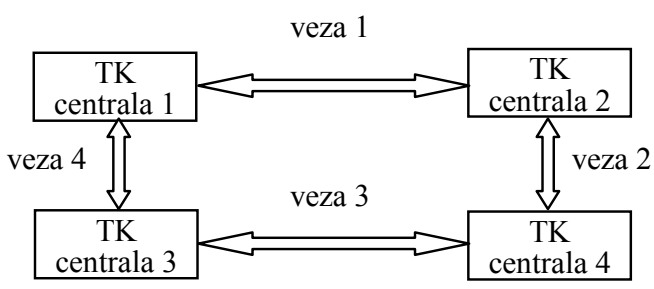

Sl. 1 - Sistem od četiri TK centrale povezane u prsten dupleks-vezama tog intervala. $\mathrm{S}$ druge strane, ako je $A(350)=0,95$ i ako je 100 takvih sistema radilo 350 časova, u proseku će na kraju tog perioda biti 95 operativnih sistema i 5 sistema u različitim fazama popravke. Iz navedenog sledi da je zahtev $R(350)=0,95$ stroži od zahteva A(350) $=0,95$, odnosno u opštem slučaju je

$R(t) \leq A(t)$

Pouzdanost i raspoloživost telekomunikacionih sistema teško je odrediti analitičkim putem, jer zahteva postavljanje i rešavanje sistema velikog broja jednačina [1]. Ovaj rad predlaže primenu simulacione metode „Monte Karlo“ za određivanje pouzdanosti i raspoloživosti telekomunikacionog sistema. U tu svrhu razvijen je odgovarajući matematičko-fizički simulacioni model i računarski program koji ga podržava [2]. Spoljne smetnje (ometanje) pri prenošenju informacija, kao ni mogući otkazi softvera nisu uzeti u razmatranje u ovom radu.

\section{Konfiguracija telekomunikacionog sistema}

Predmet razmatranja je telekomunikacioni sistem koji se sastoji od četiri telekomunikacione (TK) centrale, $n=4$, povezane u prsten dupleks-vezama prema slici 1. Telekomunikacioni sistem radi ispravno ako su sve četiri TK centrale ispravne $\mathrm{i}$ ako je moguće uspostaviti vezu između njih. Sistem ne radi ispravno ako je bar jedna TK centrala neispravna, ili ako su sve TK centrale ispravne ali ne postoji mogućnost uspostavljanja veze između svake od njih. 
Moguća su dva načina komunikacija među centralama:

- direktni (primer TK centrala 1 i 2 preko dupleks-veze 1) i

- preko tranzitne centrale (primer TK centrala 1 i 4 komuniciraju preko dupleks-veza 1 i 2 i tranzitne centrale 2 ).

TK centrale su organizovane kao primopredajnici.

\section{Određivanje pouzdanosti i raspoloživosti telekomunikacionog sistema metodom simulacije}

Za određivanje pouzdanosti i raspoloživosti telekomunikacionog sistema razmatra se sistem u periodu normalnog rada, kada su intenziteti otkaza u vremenu konstantni, a kvarovi se dešavaju, uglavnom, slučajno. Tada se koristi eksponencijalna raspodela otkaza kao matematički model da aproksimira ovaj period rada sistema.

Telekomunikacioni sistemi građeni su od većeg broja TK centrala i dupleksveza, što omogućava uspostavljanje komunikacija - većeg broja povoljnih stanja sistema, ali zato, s druge strane, znatno otežava određivanje analitičkih izraza za pouzdanost i raspoloživost sistema.

Za proračun pouzdanosti i raspoloživosti telekomunikacionih sistema potrebno je poznavati sledeće osnovne karakteristike TK centrala i linija veza:

$\lambda_{i} ; i=1,2, \ldots n-$ intenzitet otkaza TK centrala,

$\lambda_{i j} ; i \neq j ; i, j=1,2, \ldots n$-intenzitet otkaza linija veza u jednom smeru,

$\lambda_{j i} ; j \neq i ; j, i=1,2, \ldots n$-intenzitet otkaza linija veza u drugom smeru, $\mu_{i} ; i=1,2, \ldots n$-intenzitet opravke TK centrala,

$\mu_{i j} ; i \neq j ; i, j=1,2, \ldots n$-intenzitet opravke linija veza,

$$
\lambda=\frac{1}{m} ; m-\text { srednje vreme rada }
$$

do/između otkaza,

$$
\mu=\frac{1}{\tau} ; \tau-\text { srednje vreme aktivne }
$$

opravke.

Za dupleks-veze intenziteti otkaza linija veza, u oba smera, jednaki su i iznose:

$\lambda_{I J}=\lambda_{i j}+\lambda_{j i}$

Pouzdanost $R(t)$ telekomunikacionog sistema definiše se kao:

$R(t)=e^{-\lambda t}=e^{-\frac{t}{m}}$

Raspoloživost $A(t)$ telekomunikacionog sistema definiše se kao:

$$
A(t)=\frac{\mu}{\lambda+\mu}+\frac{\lambda}{\lambda+\mu} e^{-(\lambda+\mu) t}
$$

$\mathrm{Za}$ datu konfiguraciju telekomunikacionog sistema i zadate vrednosti $\lambda_{i}$, $\lambda_{i j}, \lambda_{j i}, \mu_{i}, \mathrm{i} \mu_{i j}$, prema simulacionoj metodi „Monte Karlo“, generišu se pseudoslučajni brojevi:

$t_{i}$ - vreme do otkaza TK centrala i

$t_{I J}$ - vreme do otkaza linija veza između dve TK centrale.

Kada je u pitanju pouzdanost sistema, navedena vremena otkaza sastavnih delova generišu se iz izraza za pouzdanost:

$$
\begin{aligned}
& t_{i}=-\frac{1}{\lambda_{i}} \ln R ; R \in(0,1) \\
& t_{I J}=-\frac{1}{\lambda_{I J}} \ln R ; R \in(0,1)
\end{aligned}
$$


U drugom slučaju, kada se razmatra raspoloživost sistema, navedena vremena otkaza sastavnih delova generišu se iz izraza za raspoloživost:

$$
\begin{aligned}
& \mathrm{t}_{\mathrm{i}}=-\frac{1}{\lambda_{\mathrm{i}}+\mu_{\mathrm{i}}} \ln \left[\frac{\mathrm{A} * \lambda_{\mathrm{i}}+(\mathrm{A}-1) * \mu_{\mathrm{i}}}{\lambda_{\mathrm{i}}}\right] ; \\
& \mathrm{A} \in(0,1), \\
& \left.t_{I J}=-\frac{1}{\lambda_{I J}+\mu_{I J}}\right] ; \\
& \ln \left[\frac{A * \lambda_{I J}+(A-1) * \mu_{I J}}{\lambda_{I J}}\right] \\
& \mathrm{A} \in(0,1) .
\end{aligned}
$$

Sada su $R$ i $A$ pseudoslučajni brojevi koji imaju ravnomernu raspodelu u intervalu $(0,1)$.

Ako je zadato vreme bezotkaznog rada sistema $T_{0}$, između dve razmatrane TK centrale, za sastavne delove postavljaju se dva sledeća uslova:

$$
\begin{aligned}
& t_{i}>T_{o} \mathrm{i} \\
& t_{I J}>T_{o} .
\end{aligned}
$$

Kada su ispunjena oba ova uslova, tada postoji komunikaciona veza, odnosno putanja, između ulazne TK centrale 1 i izlazne TK centrale $n$. Ukoliko ne postoji ni jedna putanja od TK centrale 1 do TK centrale $n$, smatra se da telekomunikacioni sistem nije pouzdan/raspoloživ, tj. otkazao je u odnosu na ove dve posmatrane TK centrale. U sledećoj iteraciji pokušava da se nađe nova putanja koja će zadovoljiti postavljene zahteve. Dakle, po simulacionoj metodi „Monte Karlo" svaka nova iteracija znači promenu konfiguracije telekomunikacionog sistema, jer otkazuju TK centrale i linije veza između njih. Određivanje ispravnog stanja, ispravne putanje, između ulazne-po- lazne TK centrale 1 i izlazne-dolazne TK centrale $n$ odvija se po iteracijama. Kreće se od polazne TK centrale 1, a sledeća dolazna (tranzitna) TK centrala određuje se na slučajan način (broj te tranzitne TK centrale generisan je kao pseudoslučajni broj između 1 i $n$ ).

Za slučaj da su te dve susedne TK centrale ispravne, kao i linijska veza među njima, za sledeću iteraciju dolazna (tranzitna) TK centrala postaje polazna, i postupak se nastavlja, korak po korak dalje, dok se ne dođe do željene izlazne TK centrale $n$, kao konačnog odredišta.

Ako se ne ostvari veza između polazne i dolazne TK centrale, generiše se novi pseudoslučajni broj koji predstavlja novu dolaznu (tranzitnu) TK centralu. U jednoj iteraciji, ako treba, postupak može da se ponavlja i do 1000000 puta. Ako ne uspe da se nađe ,prohodna putanja“ od TK centrale 1 do $n$ smatra se da iteracija nije uspela; putanja u stvari nije otkrivena, iako fizički veza između TK centrala 1 i $n$ možda i postoji.

Pouzdanost i raspoloživost predstavljaju verovatnoće, odnosno broj između 0 i 1 ili 0 i $100 \%$, te se mogu predstaviti kao odnos između broja uspešnih zadataka prema ukupnom broju zadataka. U našem slučaju, gde je primenjena simulaciona metoda „Monte Karlo“, $N$ je ukupan broj iteracija, a $M$ broj uspešnih iteracija, pri kojima je moguće uspostaviti vezu između ulazne i izlazne TK centrale. Tada se pouzdanost/raspoloživost telekomunikacionog sistema između dve posmatrane TK centrale može odrediti iz izraza:

$$
R=\frac{M}{N} \text {, odnosno } A=\frac{M}{N} .
$$




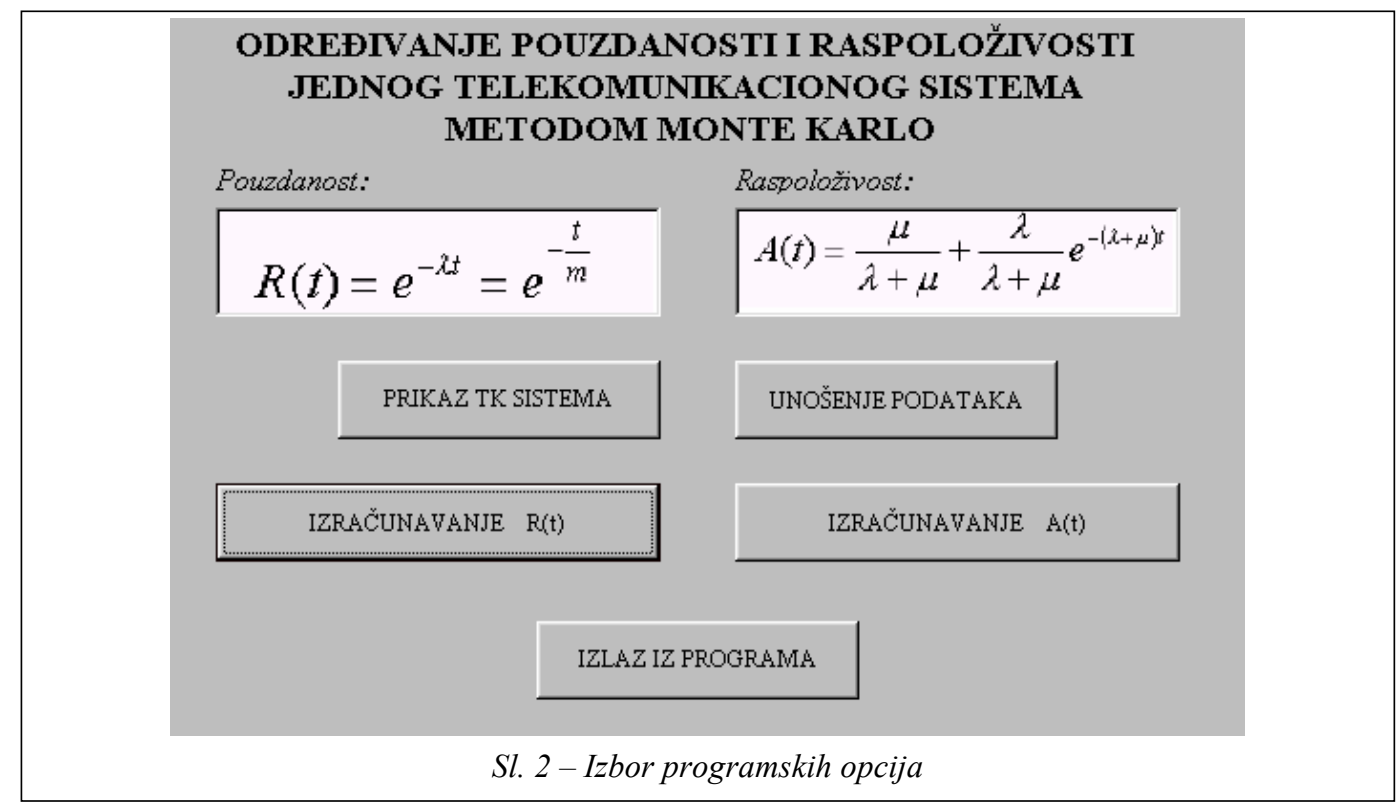

Za obe karakteristike - pouzdanost i raspoloživost, ukupan broj iteracija $N$ je isti, a broj uspešnih iteracija $M$ različit, jer se $u$ simulacioni proces ulazi sa različitim izrazima za vremena zastoja sastavnih de- lova, kako je to već opisano. Proces simulacije, po metodi „Monte Karlo“, odvija se po svim sastavnim delovima sistema prvo za jednu karakteristiku - pouzdanost, a zatim za drugu - raspoloživost.

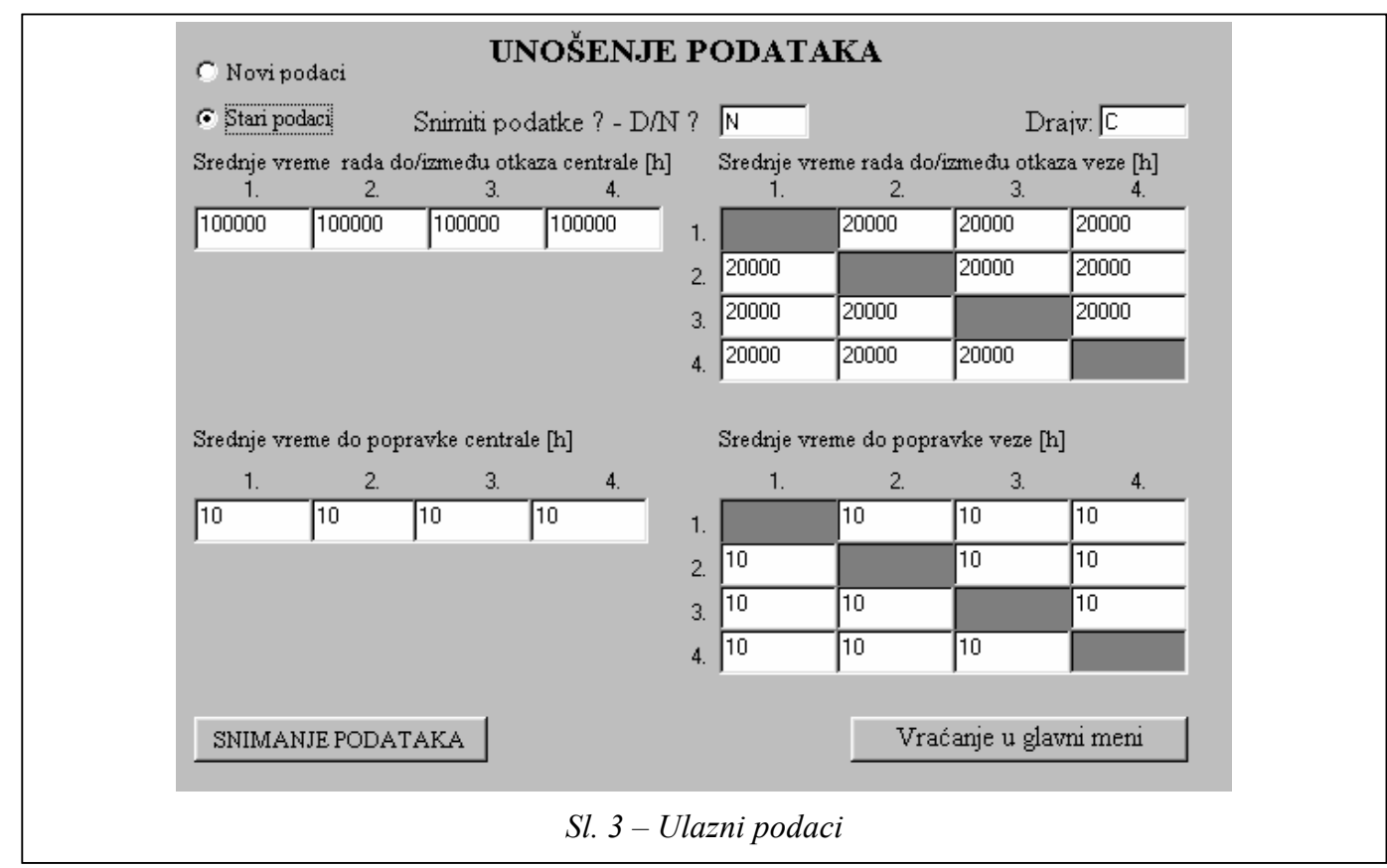




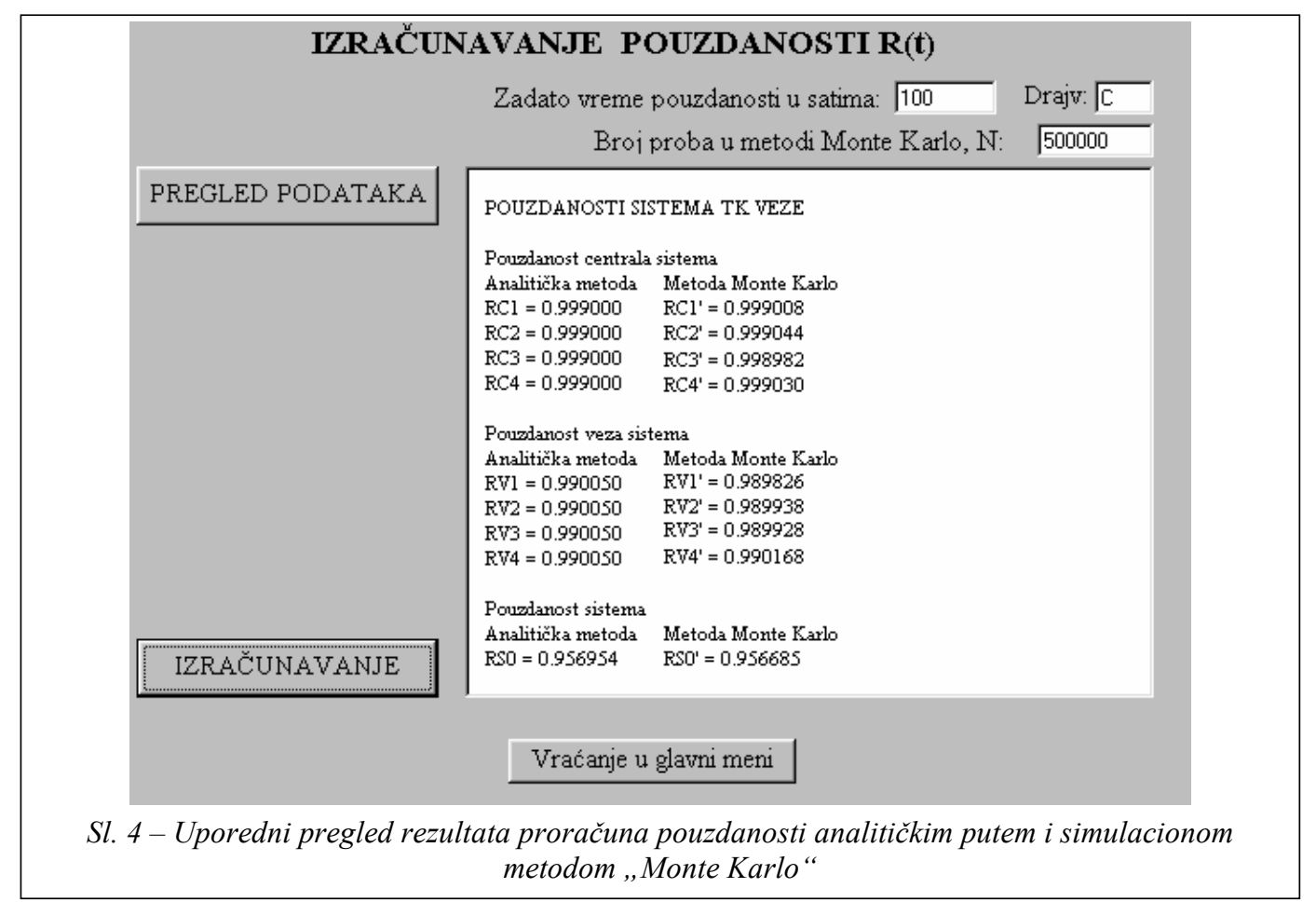

\section{Numerički primer}

Za telekomunikacioni sistem na slici 1 sve četiri TK centrale sa relevantnim dupleks-vezama su jednake. Ulazni podaci [1] za datu konfiguraciju sistema iznose:

$$
\begin{aligned}
& \lambda_{i}=0,00001 h^{-1} ; i=1,2,3,4, \\
& \lambda_{I J}=0,00005 h^{-1} ; i, j=1,2,3,4 ; i \neq j, \\
& \mu_{i}=0,1 h^{-1} ; i=1,2,3,4, \\
& \mu_{I J}=0,1 h^{-1} ; i, j=1,2,3,4 ; i \neq j .
\end{aligned}
$$

Za određivanje pouzdanosti i raspoloživosti telekomunikacionog sistema, definisanog navedenim parametrima, primenom metode „Monte Karlo“, urađen je računarski program, koji kao ulazne podatke uzima:

- srednja vremena rada do/između otkaza TK centrala i linija veza, i

- srednja vremena aktivne popravke TK centrala i linija veza.
Opcije koje nudi programski paket prikazane su na slici 2 , a unošenje ulaznih podataka na slici 3. Primenom datog programa dobijeni su rezultati proračuna pouzdanosti i raspoloživosti TK centrala, međusobnih veza, kao i kompletnog telekomunikacionog sistema (slike 4 i 5).

\section{Zaključak}

$\mathrm{S}$ obzirom na to da se radi o relativno jednostavnom primeru telekomunikacionog sistema, analitičkim putem određene su karakteristike pouzdanosti i raspoloživosti sastavnih delova i sistema. Za zadato vreme bezotkaznog rada sistema od 100 časova, uporednom analizom rezultata dobijenih analitičkom i simulacionom metodom uočljivo je da se rezultati proračuna pouzdanosti/raspoloživosti celog sistema, za 500000 proba, razlikuju tek u četvrtoj 


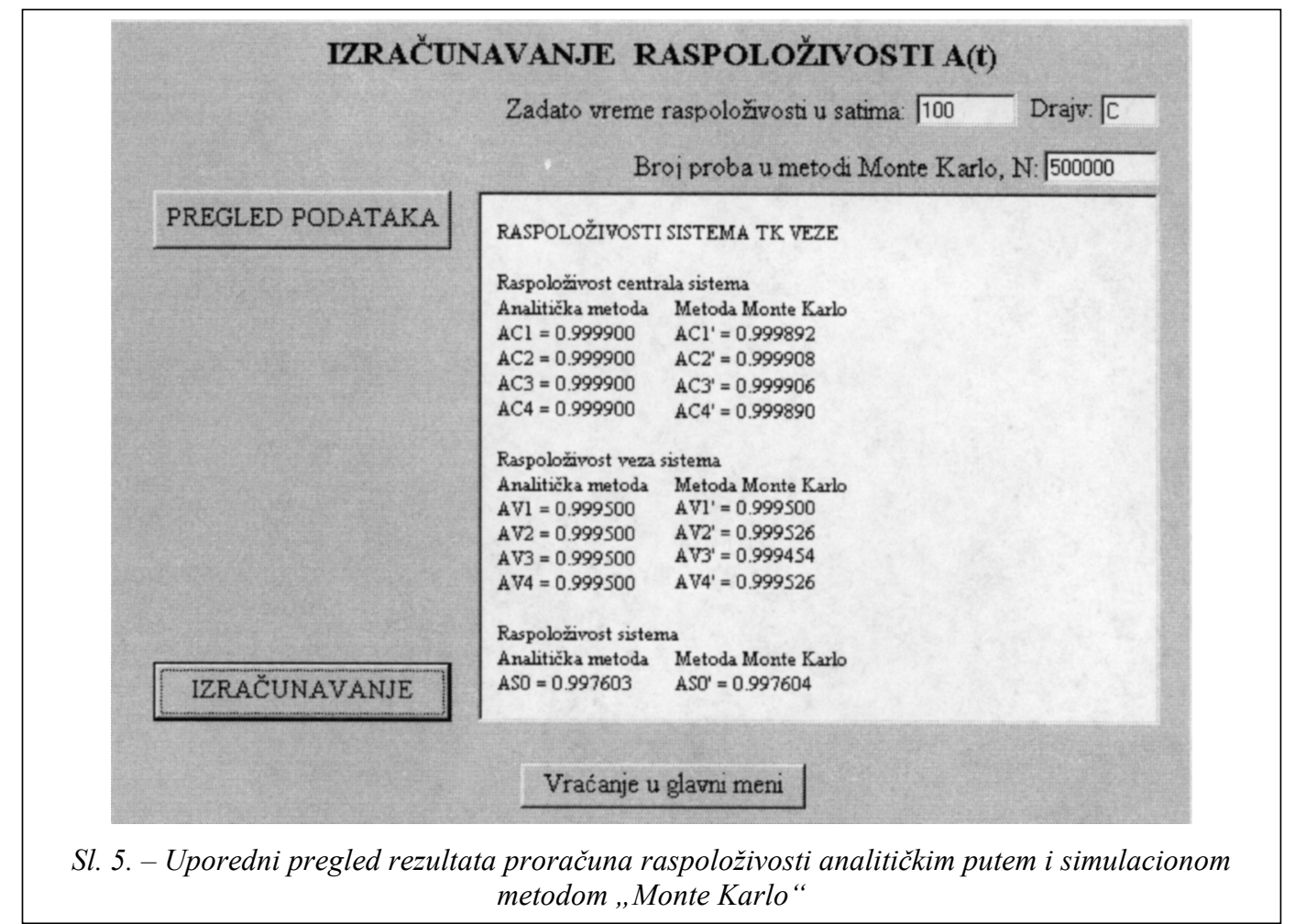

decimali, što je potvrda ispravnosti primene predložene simulacione metode „Monte Karlo" za određivanje pouzdanosti/raspoloživosti telekomunikacionog sistema. Pozitivni efekti primene predložene metode mnogo su veći kada je u pitanju složeni telekomunikacioni sistem.

Literatura:

[1] Pokorni, S.; Ramović, R.: Pouzdanost i raspoloživost različitih varijanti rezerviranja sistema sa 4 telekomunikacione centrale, Zbornik radova konferencije SYM-OP-IS, 2003, str. 439-442.

[2] Brkić, D.: Određivanje pouzdanosti komunikacione mreže metodom „Monte Karlo“, Zbornik radova konferencije SYM-OP-IS, 2001, str. 431-434.

[3] Pokorni, S.; Ramović, R.: Optimizacija pouzdanosti i troškova redundovanja jednog telekomunikacionog sistema, Zbornik radova konferencije SYM-OP-IS, 2002, str. XI-1 do XI-4.

[4] Ostojić, D.; Brkić, D.; Pokorni, S.: Određivanje raspoloživosti jednog telekomunikacionog sistema metodom ,.Monte Karlo“, Zbornik radova 9. međunarodne konferencije UPRAVLJANJE KVALITETOM I POUZDANOŠĆU DQM-2006, Beograd, 2006, str. 596-600.

[5] Vujanović, N.: Teorija pouzdanosti tehničkih sistema, Vojnoizdavački i novinski centar, Beograd, 1987. 